\title{
THz Properties of Typical Woods Important for European Forestry
}

\author{
K. Krügener ${ }^{1} \cdot$ S. Sommer ${ }^{2} \cdot$ E. Stübling ${ }^{2} \cdot$ R. Jachim ${ }^{1} \cdot$ M. Koch ${ }^{2} \cdot$ W. Viöl ${ }^{1}$
}

Received: 4 February 2019 / Accepted: 13 May 2019 /Published online: 6 June 2019

(C) The Author(s) 2019

\begin{abstract}
Terahertz (THz) properties of seventeen types of wood typically growing within the European area are investigated. The samples include both coniferous and deciduous timbers. The determined properties can be useful for further $\mathrm{THz}$ studies on samples consisting completely or partially of wood, for example, art objects. Especially in the field of art conservation, $\mathrm{THz}$ spectroscopy is an excellent non-destructive evaluation method, which shows considerable analysis potential.
\end{abstract}

Keywords $\mathrm{THz}$ spectroscopy $\cdot$ Wood $\cdot$ Coniferous $\cdot$ Deciduous

For many centuries, wood has been one of the most used basic materials to construct furniture or buildings. In addition, many important art objects have been made out of wood. Considering the value and uniqueness of such objects, the use of non-invasive methods is desired for the investigation of these objects. THz spectroscopy has this non-invasive character.

However, only a few THz studies on wood exist. For example, damage or moisture has been examined on lumber $[1,2]$, and also, the possibility of tree ring and wood density analysis has already been demonstrated [3-6]. The wood structure is partly of the same dimension as the $\mathrm{THz}$ wavelengths. This will lead to scattering of the THz waves; a fact that could make potential applications difficult, as the attenuation of $\mathrm{THz}$ waves could be caused by scattering or absorption. As this cannot be distinguished through a simple transmission or reflection measurement, the "real" dielectric parameters will be affected with an uncertainty. This could complicate experiments where knowledge of the dielectric properties of wood is crucial.

Possible $\mathrm{THz}$ applications on wooden objects include, for example, $\mathrm{THz}$ tomography on panel paintings or feeding damages on wood $[7,8]$. In order to be able to estimate the success of such an application and to be able to tomographically reconstruct the $\mathrm{THz}$ data, knowledge

\section{K. Krügener}

kirsti.kruegener@hawk.de

1 Faculty of Natural Sciences and Technology, HAWK University of Applied Sciences and Arts, Von-Ossietzky-Str. 99, 37085 Goettingen, Germany

2 Department of Physics, Philipps-Universität Marburg, Renthof 5, 35032 Marburg, Germany 
of the refractive index and the absorption coefficient in the THz range of the involved materials is important. Here, we study the THz properties of different wood specimens in the THz range using $\mathrm{THz}$ time-domain spectroscopy in transmission geometry. The samples selected are typical timber materials of trees growing within the European area. They are commonly used for art objects, furniture, as well as construction materials for buildings. Based on this data, we can estimate the application potential of $\mathrm{THz}$ radiation for the investigation of wooden objects.

\section{Samples and Method}

Overall, seventeen different types of wood were studied, which can be divided into coniferous and deciduous timbers. For coniferous trees, the common European silver fir (Abies alba), Norway spruce (Picea abies), Scots pine (Pinus sylvestris) and stone pine (Pinus), and European larch (Larix decidua) were examined. The measured deciduous trees include the durmast oak (Quercus petraea) and red oak (Quercus borealis), the European ash (Fraxinus excelsior), the horse chestnut (Aesculus hippocastanum) and sweet chestnut (Castanea sativa), the common beech (Fagus sylvatica) and common hornbeam (Carpinus betulus), the red alder (Alnus rubra), sycamore maple (Acer pseudoplatanus), and Norway maple (Acer platanoides), as well as the European white birch (Betula pendula) and littleleaf linden (Tilia cordata). Each sample had a size of $2.5 \times 2.5 \mathrm{~cm}$. The sample thickness varied between $4 \mathrm{~mm}$ and $8 \mathrm{~mm}$. All test specimens were prepared out of dried wood from the wood collection of the Faculty of Resource Management of the University Göttingen and were cut using a precision saw. The samples were prepared from the area of the sapwood directly under the bark, whose demarcation to the ripening wood and heartwood was clearly to be defined in all analyzed woods.

The samples were analyzed with a free-space terahertz time-domain spectrometer (THzTDS) in transmission configuration. All wood samples were measured at two positions to consider the inhomogeneous structure of the wood. Measurements were made against the surface of the flat area sawn into the radial direction so that the growth rings were perpendicular to the measurement direction (see Fig. 1). Subsequently, the index of refraction and the absorption coefficient as a function of frequency were evaluated for each type of wood with the aid of the commercially available TeraLyzer software [9]. The results for the two different positions in each sample were averaged.

Since the measured THz data is influenced by the density and the water content of a sample, both metrics are determined. For this purpose, the bone-dry weight was first determined. All samples were weighed at room temperature, then placed in a dry cabinet, and dried at $103 \pm$ $2{ }^{\circ} \mathrm{C}$ for $18 \mathrm{~h}$. Subsequently, they were cooled in a desiccator over silica gel for $20 \mathrm{~min}$. Afterward, the bone-dry weight was determined to an accuracy of $0.001 \mathrm{~g}$. Based on EN 13183-1: 2002 the wood moisture content was determined according to the following formula:

$$
\omega=\frac{m_{1}-m_{0}}{m_{0}} \times 100
$$

where $m_{1}$ is the mass of the specimen before drying; $m_{0}$ is the mass of the samples at the point of bone-dry weight; $\omega$ is the moisture content in percent. Based on the bone-dry weight and the determined volume of the individual samples, the respective density of the measured wood could be determined. In Table 1, the determined values for density and wood moisture, which were presented during the THz measurements on the samples, are shown. These values agree well with values reported in the literature [10]. 


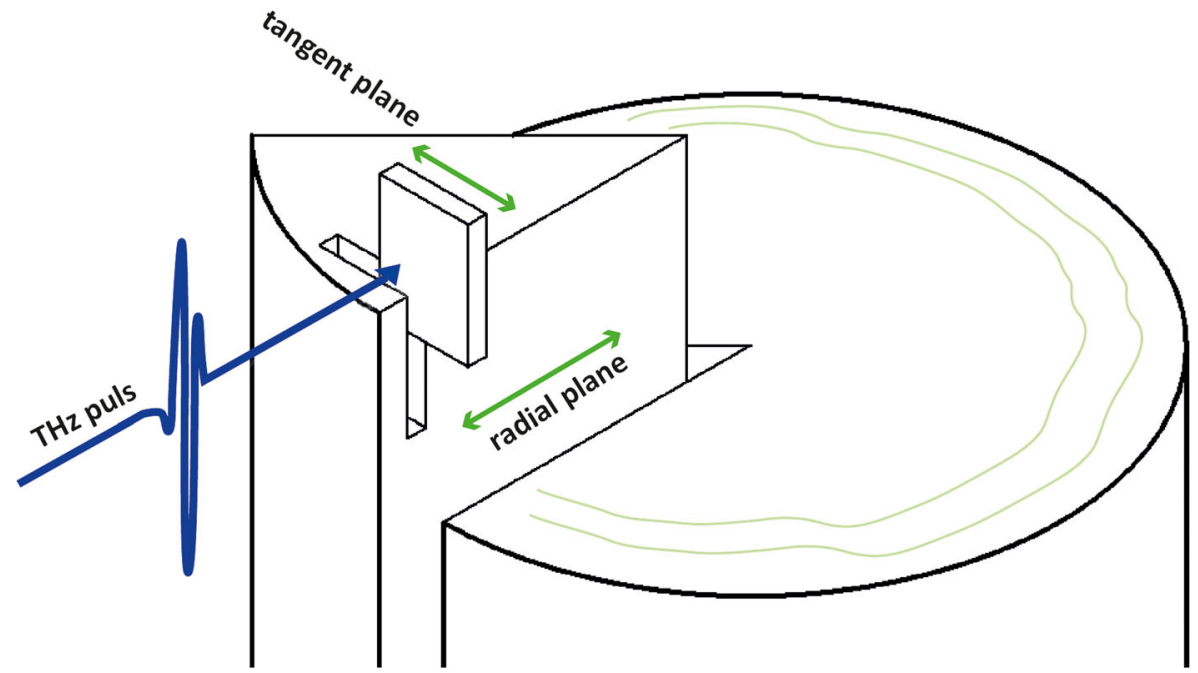

Fig. 1 Schematic of the sample preparation including tangent and radial plane and $\mathrm{THz}$ measuring direction through the sample

\section{Results}

Figure 2 shows the refractive index and "absorption coefficient" of coniferous trees. We put absorption coefficient in quotation marks as this is not the real absorption coefficient but the shown values are affects somewhat by scattering. The error bars shown represent mainly the inhomogeneous wood structure as well as systematic measurement errors. It turns out that the scots and stone pine have a similar refractive index and "absorption coefficient." In addition, the refractive index of the Norway spruce and the European larch is quite similar. However, the corresponding "absorption coefficient" is different for these two wood types.

Table 1 Determined parameters for the investigated wood samples

\begin{tabular}{|c|c|c|c|c|c|c|c|c|}
\hline \multirow[t]{2}{*}{ Wood species } & \multirow{2}{*}{$\begin{array}{l}\text { Density } \\
{\left[\mathrm{g} / \mathrm{cm}^{3}\right]}\end{array}$} & \multirow{2}{*}{$\begin{array}{l}\text { Water } \\
\text { content }[\%]\end{array}$} & \multicolumn{2}{|c|}{$0.3 \mathrm{THz}$} & \multicolumn{2}{|c|}{$0.5 \mathrm{THz}$} & \multicolumn{2}{|c|}{$0.7 \mathrm{THz}$} \\
\hline & & & $n$ & $\alpha[1 / \mathrm{cm}]$ & $n$ & $\alpha[1 / \mathrm{cm}]$ & $n$ & $\alpha[1 / \mathrm{cm}]$ \\
\hline Common European silver fir & 0.40 & 8.3 & 1.23 & 2.78 & 1.23 & 4.38 & 1.22 & 7.77 \\
\hline Norway spruce & 0.42 & 8.4 & 1.39 & 5.26 & 1.38 & 7.96 & 1.38 & 13.97 \\
\hline European Larch & 0.51 & 8.9 & 1.39 & 4.74 & 1.38 & 7.17 & 1.38 & 12.00 \\
\hline Scots pine & 0.45 & 7.4 & 1.30 & 3.74 & 1.30 & 5.30 & 1.29 & 9.52 \\
\hline Stone pine & 0.39 & 7.0 & 1.31 & 4.58 & 1.30 & 5.95 & 1.30 & 9.67 \\
\hline Durmast oak & 0.69 & 8.0 & 1.42 & 6.60 & 1.43 & 14.44 & 1.46 & 17.90 \\
\hline Red oak & 0.62 & 7.4 & 1.41 & 6.45 & 1.40 & 10.41 & 1.38 & 23.25 \\
\hline Red alder & 0.54 & 7.4 & 1.41 & 5.46 & 1.40 & 7.78 & 1.40 & 14.38 \\
\hline Horse chestnut & 0.48 & 7.7 & 1.38 & 6.68 & 1.38 & 9.09 & 1.36 & 13.58 \\
\hline Sweet chestnut & 0.48 & 7.9 & 1.38 & 4.97 & 1.38 & 9.11 & 1.37 & 13.05 \\
\hline Common beech & 0.64 & 7.8 & 1.39 & 4.71 & 1.38 & 9.40 & 1.37 & 14.49 \\
\hline Common hornbeam & 0.74 & 7.5 & 1.56 & 6.36 & 1.56 & 12.50 & 1.57 & 19.52 \\
\hline Littleleaf linden & 0.47 & 6.2 & 1.35 & 4.37 & 1.35 & 7.10 & 1.35 & 10.86 \\
\hline Sycamore maple & 0.50 & 7.7 & 1.30 & 3.61 & 1.30 & 6.33 & 1.29 & 10.21 \\
\hline Norway maple & 0.61 & 7.4 & 1.47 & 6.49 & 1.46 & 10.25 & 1.46 & 15.74 \\
\hline European white birch & 0.53 & 7.8 & 1.47 & 7.90 & 1.47 & 11.27 & 1.45 & 15.90 \\
\hline European ash & 0.64 & 7.5 & 1.47 & 7.22 & 1.46 & 11.53 & 1.47 & 16.36 \\
\hline
\end{tabular}



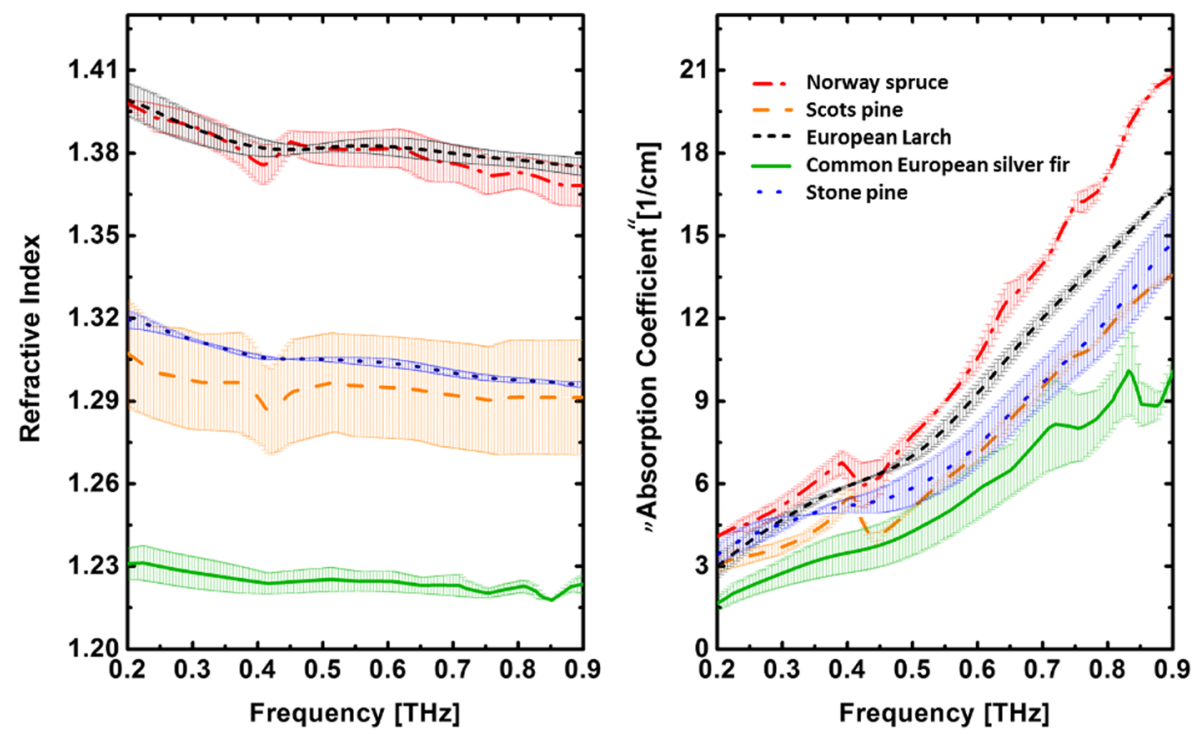

Fig. 2 Refractive index (left) and absorption coefficient (right) of coniferous shrubs

The results for the deciduous trees are summarized in Fig. 3. The common hornbeam, the littleleaf linden, and the sycamore maple exhibit a refractive index clearly different from the others. The refractive indices of the other deciduous trees are grouped into three parts. One group consists of red alder, durmast, and red oak (see Fig. 3 left panel), a second group of horse and sweet chestnut and common beech (see Fig. 3 center), and a third group of the European white birch, the European ash, and the Norway maple (see Fig. 3 right panel). The difference in the absorption coefficient is not as obvious as the difference seen in the refractive index.
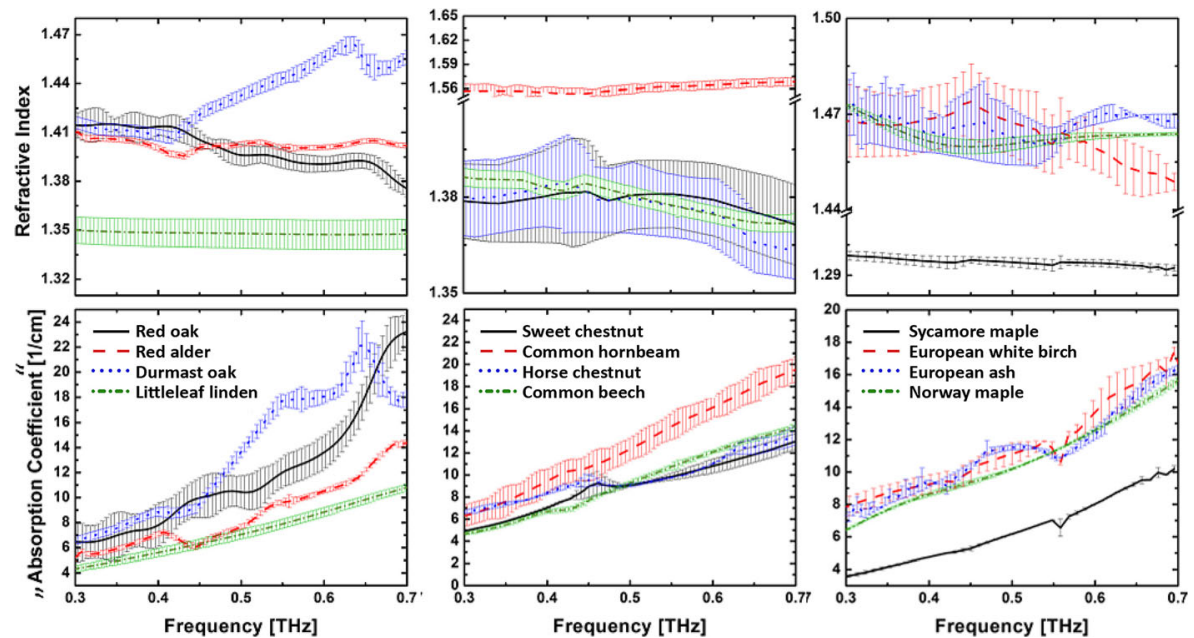

Fig. 3 Refractive index (top) and absorption coefficient (bottom) of deciduous shrubs 


\section{Discussion}

Table 1 gives an overview of the refractive indices and absorption coefficients of the wood species at different frequencies. When comparing the density and water content of the samples with the $\mathrm{THz}$ properties, no direct relationship can be found. The actual cell structure of the woods also has a major influence on the THz properties. The error bars are a measure of how reproducible and reliable the results are. This depends largely on the wood structure itself. Species with a particularly inhomogeneous structure, such as the common hornbeam, show a significantly greater fluctuation in the evaluation of the dielectric properties in the $\mathrm{THz}$ range than, for example, the stone pine, which has a more homogenous cell structure. Furthermore, the difference of wall thicknesses and the cavity of the flow cell between early and latewood must be considered. This inaccuracy will affect also the accuracy of further tomographic applications.

Overall, the study has shown that coniferous trees, in particular, are suitable for THz measurements. For deciduous trees, in particular, for the common hornbeam and the red oak, we observe larger error bars, which we attribute to sample inhomogeneities. Hence, measurement data obtained in future studies, e.g., on art objects will be affected with a higher uncertainty for these wood types.

Acknowledgments The authors would like to thank the Ministry for Science and Culture of Lower Saxony and the Funding of VW "Niedersächsisches Vorab" (Germany) for their financial support.

Funding information Financial support from both institutions.

Open Access This article is distributed under the terms of the Creative Commons Attribution 4.0 International License (http://creativecommons.org/licenses/by/4.0/), which permits unrestricted use, distribution, and reproduction in any medium, provided you give appropriate credit to the original author(s) and the source, provide a link to the Creative Commons license, and indicate if changes were made.

\section{References}

1. F. C. Beall, "Subsurface Sensing of Properties and Defects in Wood and Wood Products," Subsurf. Sens. Technol. Appl., vol. 1, no. 2, pp. 181-204, 2000.

2. Y. Oyama, L. Zhen, T. Tanabe, and M. Kagaya, "Sub-terahertz imaging of defects in building blocks," NDT E Int., vol. 42, no. 1, pp. 28-33, 2009.

3. M. Koch, S. Hunsche, P. Schumacher, M. C. Nuss, J. Feldmann, and J. Fromm, "THz-imaging: A new method for density mapping of wood," Wood Sci. Technol., vol. 32, no. 6, pp. 421-427, 1998.

4. J. B. Jackson et al., "Terahertz pulse imaging for tree-ring analysis: a preliminary study for dendrochronology applications," Meas. Sci. Technol., vol. 20, no. 7, p. 075502, 2009.

5. T. Inagaki, I. D. Hartley, S. Tsuchikawa, and M. Reid, "Prediction of oven-dry density of wood by timedomain terahertz spectroscopy," Holzforschung, vol. 68, no. 1, pp. 61-68, 2014.

6. M. Koch, "THz imaging: fundamentals and biological applications," in Terahertz Spectroscopy and applications II, 1999, p. 3828.

7. I. Catapano, M. Picollo, and K. Fukunaga, "Terahertz Waves and Cultural Heritage: State-of-the-Art and Perspectives," in Sensing the past, vol. 16, N. Masini and F. Soldovieri, Eds. Springer, 2017, pp. 313-323.

8. C. L. Koch Dandolo, A. Cosentino, and P. U. Jepsen, "Inspection of panel paintings beneath gilded finishes using terahertz time-domain imaging," Stud. Conserv., vol. 60, no. sup1, pp. S159-S166, 2015.

9. M. Scheller, C. Jansen, and M. Koch, "Analyzing sub-100- $\mu \mathrm{m}$ samples with transmission terahertz time domain spectroscopy,” Opt. Commun., vol. 282, no. 7, pp. 1304-1306, 2009.

10. R. Wagenführ, Holzatlas, 6th ed. Carl Hanser Verlag GmbH \& Co. KG, 2006.

Publisher's Note Springer Nature remains neutral with regard to jurisdictional claims in published maps and institutional affiliations. 